\title{
Diffuse axonal injury in head trauma
}

\author{
PETER C BLUMBERGS, NIGEL R JONES, JOHN B NORTH
}

\author{
From the Neuropathology Laboratory, Institute of Medical and Veterinary Science and Neurosurgery \\ Department, Royal Adelaide Hospital, Adelaide, South Australia
}

SUMMARY Diffuse axonal injury (DAI) as defined by detailed microscopic examination was found in 34 of 80 consecutive cases of head trauma surviving for a sufficient length of time to be clinically assessed by the Royal Adelaide Hospital Neurosurgery Unit. The findings indicate that there is a spectrum of axonal injury and that one third of cases of DAI recovered sufficiently to talk between the initial head injury producing coma and subsequent death. The macroscopic "marker" lesions in the corpus callosum and dorsolateral quadrants of the brainstem were present in only 15/34 of the cases and represented the most severe end of the spectrum of DAI.

Diffuse axonal injury (DAI) that is, widespread damage to axons in the white matter of the brain, was originally defined by Strich ${ }^{1}$ and the concept was expanded by Adams et al. ${ }^{2}$ Strich described diffuse degeneration of the cerebral white matter in a series of patients with severe post traumatic dementia and in a subsequent paper concluded that the axonal damage was produced by mechanical forces shearing the fibres at the moment of impact. ${ }^{3}$ Since her original observations the same pathological process has been described by others as "shearing injury", "diffuse damage of immediate impact type"s and "diffuse white matter shearing injury". ${ }^{6}$ This concept of DAI has not remained unchallenged and some workers maintain that it arises as a secondary event due to hypoxic damage, post traumatic oedema or to secondary compression of the brainstem as a result of tentorial herniation. $^{78}$

A major advance in this field has occurred recently since Gennarelli and his group ${ }^{910}$ have shown that similar clinical and structural changes can be produced experimentally in subhuman primates using non-impact controlled angular acceleration of the head in the absence of any increase in ICP or hypoxaemia. Adams et $a l^{2}$ reported a detailed neuropathological analysis of 45 cases and defined the characteristic features of DAI as (1) focal lesions in the corpus callosum and dorsolateral quadrant (or quadrants) of the rostral brainstem adjacent to the

Address for reprint requests: Dr P C Blumbergs, Institute of Medical and Veterinary Science, Box 14, Rundle Mall PO, Adelaide, SA 5000.

Received 19 July 1988 and in revised form 22 February 1989. Accepted 7 March 1989 superior cerebellar peduncles, (2) evidence of diffuse damage to axons.

Patients who sustain severe DAI are unconscious from the moment of impact, do not experience a lucid interval, and remain unconscious, vegetative or at least severely disabled until death. Their clinical state has been referred to in the past by some as primary brainstem injury, but although there is damage to the brainstem in DAI, it is always accompanied by evidence of diffuse brain damage." DAI occurs most commonly in patients injured in road traffic accidents ${ }^{2}$ and rarely in association with simple falls. ${ }^{12}$

\section{Materials and methods}

Diffuse damage to axons can only be detected microscopically in appropriately stained tissue; it takes the forms of axonal retraction balls (RB) in short survivors (hours to days) ${ }^{13}$ microglial stars in cases of intermediate survival (several days to weeks) ${ }^{2}$ or evidence of degeneration of fibre tracts in the white matter in patients who survive for many weeks or months. ${ }^{2}$

The present study was undertaken to investigate the extent of axonal injury (AI) in a series of $\mathbf{4 2 6}$ fatal head injuries. Eighty five were patients who survived a sufficient length of time to be managed by the Neurosurgery Department of the Royal Adelaide Hospital. Excluded from further analysis were 341 road traffic accident victims who had not survived long enough to reach a hospital and five patients with gunshot wounds. This left a total of 80 brains of patients who survived for a sufficient length of time for conscious level to be assessed by the Royal Adelaide Hospital Neurosurgery Unit using the Glasgow Coma Scale. ${ }^{14}$ These clinical data were used to define a group of 11 patients, all of whom had been rendered unconscious by the initial head injury, but who recovered and talked at some point between the time of injury and death. ${ }^{15}$ These patients were classified as having had a lucid interval. 


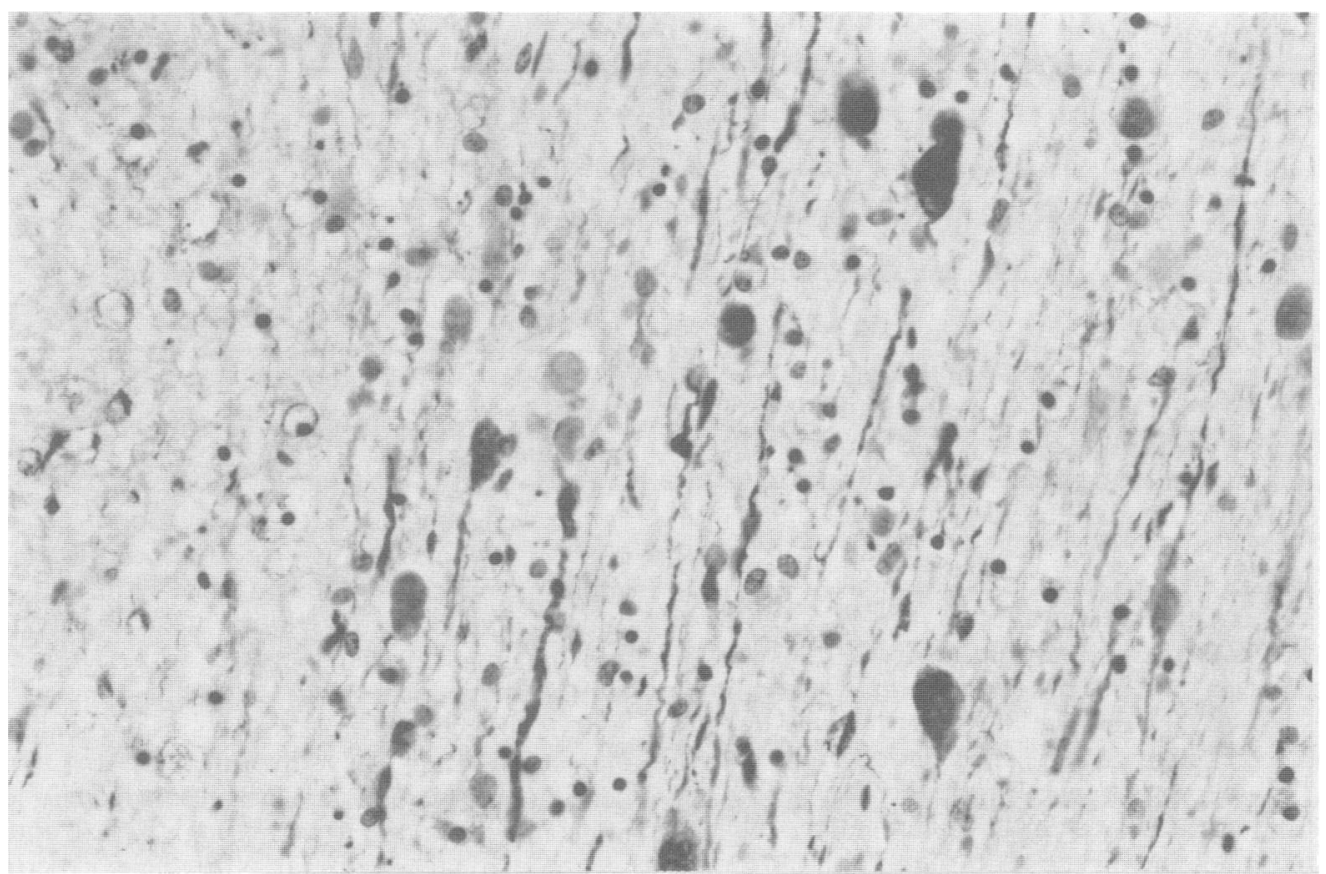

Fig Axonal retraction balls and swellings in corpus callosum. Immunochemical stain for neurofilament proteins $(N F P) .(\times 200)$

The brains were analysed in a manner similar to that developed by Hume Adams and his group ${ }^{16}$ and in addition serial whole brain sections were microscopically assessed. Detailed descriptions of the neuropathological findings were made in all cases. Any lesions found (including skull and scalp injuries) were charted on a series of line diagrams of the skull, cerebral hemispheres, brainstem and cerebellum: macroscopic abnormalities were recorded photographically. The cerebral hemispheres were cut in $1 \mathrm{~cm}$ thick slices in the coronal plane and whole brain paraffin sections prepared of each slice and stained by Nissl's method using cresyl violet, Weil stain for myelin, haematoxylin and eosin (H \& E) and various other techniques as appropriate. The cerebellum was sectioned in the sagittal plane and representative blocks stained as above. The brainstem was sliced into nine blocks and two representative sections each of midbrain, pons and medulla were stained by the $H \& E$, Nissl and Weil methods.

Axonal injury was assessed by the presence of retraction balls (RBs) not associated with focal lesions (fig). RBs were easily identified in $\mathrm{H}$ \& $\mathrm{E}$ stained sections as eosionphilic round, oval or elongated masses of varying size depending on the direction of sections but were particularly well demonstrated by silver methods such as the Glees and Marsland and Palmgren techniques for axons, which were routinely used on the brainstem and corpus callosum blocks. Immunocytochemical techniques for neurofilament proteins which specifically identify axons were also used on selected cases and axonal swellings could be identified within 1-2 hours by this method whereas with silver stains they became visible at eight hours. Retraction balls and axonal swellings are termed the microscopic markers of DAI. All focal lesions were carefully noted as RBs and axonal swellings are frequently found around infarcts ${ }^{2}$ (especially in the brain stem) and haemorrhages. A case was classified as mild DAI when at least a few unequivocal RBs were found. When RBs were numerous and widespread, AI was classified as severe. In addition, in all cases the "macroscopic lesions" (tears, haemorrhages and infarcts) were looked for in the corpus callosum and dorsolateral brain stem and recorded: these are termed macroscopic markers of DAI. Using these markers we have classified our cases into four groups.

(1) Corpus callosum and dorsolateral quadrant of brain stem.

(2) Corpus callosum only

(3) Dorsolateral quadrant of brain stem only

(4) No lesions in corpus callosum or dorsolateral quadrant of brain stem.

\section{Results}

Evidence of DAI was found in $\mathbf{3 4}$ of the 80 cases that survived to reach the Royal Adelaide Hospital.

\section{Survival times}

The survival times for these cases compared with those without DAI are seen in table 1. 
Table 1 Survival time

\begin{tabular}{lllllllll}
\hline \multicolumn{10}{c}{ Survival time } \\
\cline { 3 - 8 } & $N$ & $\begin{array}{l}1-8 \\
\text { hrs }\end{array}$ & $\begin{array}{l}8-24 \\
\text { hrs }\end{array}$ & $\begin{array}{l}24-48 \\
\text { hrs }\end{array}$ & $\begin{array}{l}2-7 \\
\text { days }\end{array}$ & $\begin{array}{l}1-4 \\
\text { weeks }\end{array}$ & $\begin{array}{l}>4 \\
\text { weeks }\end{array}$ \\
\hline DAI present & 34 & 3 & 3 & 2 & 13 & 7 & 6 \\
DAI absent & 46 & 12 & 16 & 2 & 11 & 4 & 1 \\
\hline
\end{tabular}

\section{Causes of injury}

Table 2 shows the breakdown as to the type of accident. Traffic accidents were the leading cause of head injury. In five cases, the injuries resulted from falls; in four of these, the patient fell from a considerable height, greater than the person's own height.

\section{Distribution of DAI}

The corpus callosum was affected in $94 \%$ of the cases with AI, the internal capsule in $86 \%$, the cerebral white matter in $79 \%$, the fornices in $76 \%$, the midbrain in $78 \%$, the pons in $88 \%$, the medulla in $36 \%$ and the cerebellum in $72 \%$. The microscopic markers of AI were present in both the cerebrum (corpus callosum, fornices, cerebral white matter, internal capsule) and the brainstem (midbrain, pons and medulla) in all 34 cases. However, an analysis of the macroscopic markers (see table 3 ) showed that only $15 / 34$ cases had lesions in both the corpus callosum and dorsolateral quadrant of brainstem, whereas $8 / 34$ had corpus callosum lesions alone, 3/34 dorsolateral quadrant of brainstem lesions alone and eight showed no macroscopic markers at all.

\section{Conscious level after injury}

None of the 15 cases with both corpus callosum and dorsolateral quadrant markers experienced a lucid interval.

Groups 2 (CC alone), 3 (DLQ alone) and 4 (no lesions CC or DLQ) were different from group 1 (CC and DLQ lesions). Although these patients also lost conscioussness with the injury, $50 \%$ then experienced a partial lucid interval; this was most apparent in group 4 where six of eight patients experienced a lucid interval. Cases with a partial lucid interval were associated with a high incidence of mild DAI (6/8, $75 \%)$.

Table 2 Type of head trauma

\begin{tabular}{lcc}
\hline Type of head trauma & DAI present & DAI absent \\
\hline Pedestrian & 12 & 18 \\
Car occupant & 10 & 11 \\
Motor cyclist & 7 & 6 \\
Fall & 5 & 9 \\
Crush & & 1 \\
Unknown & & 1 \\
\hline
\end{tabular}

Table 3 Duration of inability to speak-DAI group

\begin{tabular}{|c|c|c|c|c|c|}
\hline \multirow{2}{*}{$\begin{array}{l}\text { Macroscopic } \\
\text { markers }\end{array}$} & \multirow[b]{2}{*}{$N$} & \multirow{2}{*}{$\begin{array}{l}\text { Never spoke } \\
\text { after injury }\end{array}$} & \multirow{2}{*}{$\begin{array}{l}\text { Recovered } \\
\text { to lucid } \\
\text { interval }\end{array}$} & \multicolumn{2}{|c|}{$\begin{array}{l}\text { Diffuse Axonal } \\
\text { Injury }\end{array}$} \\
\hline & & & & Severe & Mild \\
\hline \multirow{2}{*}{$\begin{array}{l}\text { CC + DLQ } \\
\text { CC alone } \\
\text { DLQ alone } \\
\text { no lesion CC } \\
\text { + DLQ }\end{array}$} & $\begin{array}{r}15 \\
8 \\
3\end{array}$ & $\begin{array}{l}0 \\
4 \\
2\end{array}$ & $\begin{array}{l}0 \\
4 \\
1\end{array}$ & $\begin{array}{r}12 \\
7 \\
3\end{array}$ & $\begin{array}{l}3 \\
1\end{array}$ \\
\hline & 8 & 2 & 6 & 2 & 6 \\
\hline
\end{tabular}

\section{Discussion}

DAI is well recognised as the most common structural abnormality underlying severe neurological disability ${ }^{17}$ and the vegetative state $^{18}$ following head injury. Our findings of variation in the severity of DAI, and that one third of the cases with DAI were not permanently unconscious from the time of injury support the concept of a spectrum of axonal injury. Gennarelli et $a^{910}$ have hypothesised that there is a continuum of axonal damage varying from functional abnormalities alone to increasingly severe and widespread axonal disruption. In their experimental studies on primates ${ }^{910}$ they have graded axonal injury into three grades of severity. Grade 1 DAI consisted of scattered axonal retraction balls in the parasagittal white matter of the cerebral hemispheres. Grade 2 DAI was characterised by a histologically demonstrable focal lesion in the corpus callosum in addition to axonal damage in the white matter of the cerebral hemisphere. In grade 3 DAI focal lesions were present in the dorsolateral quadrant of the rostral brain stem and the corpus callosum in addition to axonal damage in the white matter of the hemispheres. They concluded that the amount and distribution of axonal damage as measured by the grades of DAI correlated well with the duration and severity of coma and the eventual outcome. The grade 3 DAI produced in this primate model is identical with our group I cases (corpus callosum and dorsolateral quadrant lesions) and our group 4 (no macroscopic lesions) would correlate with their DAI type 1 which was characterised only by microscopic axonal damage.

Pilz $^{19}$ also found a spectrum of axonal injury in 100 of 324 cases of unselected fatal head injuries and noted that about one third of the cases of DAI were not permanently unconscious after their injury. We found macroscopic lesions in both the corpus callosum and brain stem (DAI grade 3) in 15/34 of our cases and Pilz ${ }^{15}$ also found that the majority of his cases showed no focal accentuation of damage in these structures. Adams et $a^{20}$ have recently completed an analysis of 635 fatal head injuries and found 82 cases of DAI of which eight were examples of microscopic diffuse 
axonal injury. Four of these eight patients experienced a partial lucid interval.

Further evidence in support for a continuum of axonal injury is provided by experimental work in cats $^{22}$ which has shown that minor head injury can produce impaired anterograde axonal transport, axonal swelling and then separation of axons as a progressive phenomenon is the absence of any focal parenchymal or vascular damage. Six of the eleven patients with a lucid interval had only microscopic evidence of DAI. None of the fifteen patients with macroscopic markers of DAI exhibited a lucid interval.

In conclusion, we believe that patients with DAI show a spectrum of axonal injury and that the macroscopic "marker" lesions in the corpus callosum and dorsolateral quadrants of the brain stem are only present in the brains of those patients with the most severe DAI. One third of our cases in whom DAI was found at necropsy were not permanently unconscious from the time of injury.

This investigation was supported by the NH \& MRC Road Accident Research Unit under the Directorship of Dr A J McLean. The authors appreciate the contribution of Professor D A Simpson in reviewing the manuscript and Mrs E Kosmala for her secretarial support. For financial support, we thank the Neurosurgical Research Foundation of South Australia and the State Government Insurance Commission.

\section{References}

1 Strich SJ. Diffuse degeneration of the cerebral white matter in severe dementia following head injury. $J$ Neurol Neurosurg Psychiatry 1956;19:163-85.

2 Adams JH, Graham DI, Murray LS, Scott G. Diffuse axonal injury due to nonmissile head injury in humans: an analysis of 45 cases. Ann Neurol 1982;12:557-63.

3 Strich SJ. Shearing of nerve fibres as a cause of brain damage due to head injury. Lancet 1961 ;ii:443-8.
4 Peerless SJ, Rewcastle NB. Shear injuries of the brain. Can Med Assoc $J$ 1967;96:577-82.

5 Adams JH, Mitchell DE, Graham DI, Doyle D. Diffuse brain damage of immediate impact type. Its relationship to "primary brain stem damage" in head injury. Brain 1977;100:489-502.

6 Zimmerman RA, Bilaniuk LT, Gennarelli TA. Computerised tomography of shearing injuries of the cerebral white matter. Radiology 1978;127:393-6.

7 Jellinger J. Pathology and pathogenesis of apallic syndromes following closed head injuries. In: The Apallic Syndrome, Ore G H, Gerstenbrand F, Lucking C H, Peters G, Peters UH, eds. Berlin: Springer-Verlag, 1977:88-103.

8 Jellinger K, Seitelberger F. Protracted post-traumatic encephalopathy. Pathology, pathogenesis and clinical implications. J Neurol Sci 1970;10:51-94.

9 Gennarelli TA, Thibault LE, Adams JH, Graham DI, Thompson CJ, Marcinin RP. Diffuse axonal injury and traumatic coma in the primate. Ann Neurol 1982;12:564-74.

10 Gennarelli TA, Thibault LE, Adams JH, Graham DI, Thompson CJ, Marcinin RP. Diffuse axonal injury and traumatic coma in the primate. In: Dacey RG et al (eds.) Trauma of the Central Nervous System. New York: Raven Press, 1985;169-93.

11 Mitchell DE, Adams JH. Primary focal impact damage to the brain stem in blunt head injuries: does it exist? Lancet 1973;ii:215-8.

12 Adams JH, Doyle D, Graham DI, Lawrence AE, McLellan DR. Diffuse axonal injury in head injuries caused by a fall. Lancet 1984;ii:1420-2.

13 Rand CW, Courville CB. Histologic changes in the brain in cases of fatal injury to the head. Arch Neurol Psychiatry 1934;31: 527-55.

14 Teasdale G, Jennett B. Assessment of Coma and Impaired Consciousness. Lancet 1974;ii:81-4.

15 Reilly PL, Adams JH, Graham DI, et al Patients with head injury who talk and die. Lancet 1975;ii:375-7.

16 Adams JH, Graham DI, Scott G, Parker LS, Doyle D. Brain damage in fatal non-missile head injury. J Clin Pathol 1980;33:1132-45.

17 Jennett B, Bond MR. Assessment of outcome after severe brain damage: a practical scale. Lancet 1975;i:480-4.

18 Graham DI, McLellan D, Adams JH, Doyle D, Kerr A, Murray LS. The neuropathology of the vegetative state and severe disability after non-missile head injury. Acta Neurochir, 1983;suppl 32:65-7.

19 Pilz P. Axonal injury in head injury. Acta Neurochir 1983:Suppl 32:119-23.

20 Adams JH, Doyle D, Graham DI, Lawrence AE, McLellan DR. Microscopic diffuse axonal injury in cases of head injury. Med Sci Law 1985;25:265-9.

21 Povlishock JT, Becker DP, Cheng CLY, Vaughan GW. Axonal change in minor head injury. $J$ Neuropathol Exp Neurol 1983;42:225-42. 